\title{
High load capacity spur gears with conchoidal path of contact
}

\author{
Pavlo Tkach ${ }^{1}$ (D), Pavlo Nosko ${ }^{2}$ (D), Oleksandr Bashta ${ }^{2}$ (D), Yurii Tsybrii ${ }^{3,}{ }^{*}$ (D), and Oleksii Nosko ${ }^{3}$ (D) \\ ${ }^{1}$ E.O. Paton Electric Welding Institute of the National Academy of Sciences of Ukraine, 11 K. Malevycha st., Kyiv 03150, \\ Ukraine \\ ${ }^{2}$ National Aviation University, Department of Engineering Science, 1 L. Huzara ave., Kyiv 03058, Ukraine \\ ${ }^{3}$ Bialystok University of Technology, Faculty of Mechanical Engineering, 45C Wiejska st., Bialystok 15351, Poland
}

Received: 22 September 2020 / Accepted: 13 October 2021

\begin{abstract}
The present study is devoted to investigation of spur gears with a conchoidal path of contact and a convex-convex contact between teeth. The load capacity and energy efficiency were evaluated using both theoretical and experimental approaches. The theoretical analysis showed that the conchoidal gear pairs are 5-21\% stronger in terms of contact stress and have similar energy efficiency as compared to the involute gear pairs of the same configuration. Experiments were conducted on a gear test rig. Its energy efficiency was determined by measuring the active power of the motor driving the pinion shaft and controlling the torque at the gear shaft. The load capacity of the tested gear pair was estimated by analysing changes in the energy efficiency. It was found that the conchoidal gear pair has more than $20 \%$ higher load capacity and slightly higher energy efficiency, which agrees well with the mentioned theoretical results. Thereby, the study concludes a substantially higher load capacity of the conchoidal gears compared to the traditional involute ones.
\end{abstract}

Keywords: Spur gears / involute gears / conchoidal path of contact / load capacity / contact strength / energy efficiency

\section{Introduction}

Gears are widely used to transmit motion and energy in mechanical systems. It is difficult to imagine a modern transport machine that does not include gear trains. The most commonly used gears have teeth with an involute active profile generated by straight lines. The set of instantaneous contact points between such teeth forms a straight path of contact. The advantages of involute gears include high manufacturability, relatively small sensitivity to centre distance errors and simplicity of the reference profile. However, relatively large curvatures of the mating teeth result in large contact stresses, which strongly limits the load capacity of involute gears. Therefore, development of non-involute gear drives has a significant scientific and practical interest.

Helical gears with a circular-arc tooth profile were proposed by Wildhaber [1] and Novikov [2], subsequently called 'Wildhaber-Novikov gears'. Novikov's idea is that the contact between gears should take place at a point moving along a tooth. The active profile of one tooth is generated by a convex arc, while that of the mating tooth is generated by a concave arc of a slightly larger radius.

\footnotetext{
* e-mail: y.tsybrii@pb.edu.pl
}

Accordingly, the convex-concave contact between teeth is characterised by a reduced curvature, which leads to smaller contact stresses. But a serious disadvantage of Wildhaber-Novikov gears can be found in increased bending stresses in teeth due to the point contact. A comprehensive analysis of this type of gears was performed in the studies [3,4].

Wildhaber-Novikov concept of gearing served as the basis for the development of various circular-arc tooth profiles. One of the successful technical solutions is the application of double circular-arc tooth profile helical gears [5] (p. 158). The reference profile for generating teeth active profiles is composed of two conjugated circular arcs: convex addendum arc and concave dedendum arc. Accordingly, the convex addendums interact with the concave dedendums of the respective pinion and gear teeth. The parameters of two circular arcs are sought to minimise both contact stresses and bending stresses in teeth [6]. The other known technical solutions include (but are not limited to) gears with basic rack of combined circular and involute profile [7], circular-arc tooth pinion on involute tooth gear [8], point-line meshing gears [9], circular-arc curvilinear tooth gears [10], stepped triple circular-arc tooth gears [11], double circular-arc tooth gears modified by tooth end relief with helix [12], double circular-arc tooth gears optimised for harmonic drives [13]. 
As concerns spur gears, various alternative tooth shapes were proposed to improve the load capacity of gear drives. It is important to name, for instance, gears with zero relative curvature at many contact points [14], gears with linear profile modification [15], gears with quadratic parametric tooth profile [16], tooth profile relief design gears [17], asymmetric tooth gears [18], gears designed by usage of NURB deviation function technique [19], gears designed by B-spline curve fitting and sweep surface modelling [20], gears with multi-segment path of contact [21], cosine tooth gears [22], s-gears designed for wind power turbine operating conditions [23], gears with parabolic path of contact [24], gears with a constant relative curvature [25], gears with a circular arc contact path [26]. Although the mentioned technical solutions were shown to be effective for particular applications and operating conditions, their widespread implementation is limited by the difficulties related to manufacturing complex-shaped teeth.

A relatively simple double circular-arc reference profile for spur gears was proposed in the study [27]. The path of contact of these gears represents a conchoid of Nicomedes. Therefore, they are sometimes referred to as 'conchoidal path-of-contact gears' or 'conchoidal gears'. The study [28] investigated the conchoidal gears with convex-concave contact between teeth and concluded their better meshing and performance characteristics compared to the involute gears. Their disadvantage, however, is an increased sensitivity to manufacturing and mounting errors [29] (p. 33). The study [30] showed that the tooth profiles of the conchoidal gears can be designed to allow a convex-convex contact, which can potentially eliminate the mentioned above disadvantage. To the best authors' knowledge, this potentially promising type of conchoidal gears has not been investigated in terms of load capacity and energy efficiency yet. With this in mind, the purpose of the present study was to theoretically and experimentally investigate the load capacity of the conchoidal path-of-contact spur gears with convex-convex contact between teeth as compared to the traditional involute gears.

\section{Theory}

\subsection{Geometry of the conchoidal gears}

Figure 1 presents a geometric description of the conchoidal gears under consideration. Figure 1a shows the generating surface defined in a coordinate system $x_{\mathrm{g}} O_{\mathrm{g}} y_{\mathrm{g}}$. Figure $1 \mathrm{~b}$ introduces the pitch circles of the pinion 1 and gear 2 and the path of contact. Note that the coordinate systems $x_{1} O_{1} y_{1}$ and $x_{2} O_{2} y_{2}$ are aligned with the respective pinion 1 and gear 2, whereas $X O Y$ is the fixed coordinate system with centre $O$ at the pitch point.

The generating surface is based on the reference profile shown in Figure 1c. The curves $O_{\mathrm{g}} A$ and $O_{\mathrm{g}} B$ form the active profile of a tooth, while $O_{\mathrm{g}}^{\prime} A^{\prime}$ and $O_{\mathrm{g}}^{\prime} B^{\prime}$ form the active profile of the adjacent tooth. The curve $A A^{\prime}$ is responsible for generation of the tooth root fillet.
The coordinates of the tooth active profile are expressed separately for the curve $O_{\mathrm{g}} A$

$$
\begin{aligned}
& x_{\mathrm{g}}=x-a+\rho \sin \alpha ; \\
& y_{\mathrm{g}}=b-\rho \cos \alpha
\end{aligned}
$$

curve $O_{\mathrm{g}} B$

$$
\begin{aligned}
& x_{\mathrm{g}}=x+a-\rho \sin \alpha ; \\
& y_{\mathrm{g}}=-b+\rho \cos \alpha
\end{aligned}
$$

curve $O_{g}^{\prime} A^{\prime}$

$$
\begin{aligned}
& x_{\mathrm{g}}=x-a+\rho \sin \alpha ; \\
& y_{\mathrm{g}}=\pi / 2-b+\rho \cos \alpha
\end{aligned}
$$

and curve $O_{\mathrm{g}}^{\prime} B^{\prime}$

$$
\begin{aligned}
& x_{\mathrm{g}}=x+a-\rho \sin \alpha ; \\
& y_{\mathrm{g}}=\pi / 2+b-\rho \cos \alpha .
\end{aligned}
$$

Here $\alpha$ is the reference profile angle varying from $\alpha_{\mathrm{w}}$ to $\alpha_{\max } ; \alpha_{\mathrm{w}}$ is the reference profile angle at the pitch line (point $\left.O_{\mathrm{g}}\right) ; \alpha_{\max }$ is the maximum reference profile angle (points $A$ and $B) ; \rho$ is the profile circle radius; $x$ is the reference profile shift coefficient; parameters $a$ and $b$ are given by

$$
\begin{aligned}
& a=\rho \sin \alpha_{\mathrm{w}} ; \\
& b=\rho \cos \alpha_{\mathrm{w}} .
\end{aligned}
$$

It is important to note that equations (1)-(4) and the following equations incorporating geometric parameters are normalised for the module $m$ equal to $1 \mathrm{~mm}$.

Assume that the reference profile is symmetrical. Then it is sufficient to consider the active profile formed only by the curves $O_{\mathrm{g}} A$ and $O_{\mathrm{g}} B$. The coordinates of the active profile, given by equations (1) and (2), are represented in a concise form:

$$
\begin{aligned}
& x_{\mathrm{g}}=a \mp a \pm \rho \sin \alpha \\
& y_{\mathrm{g}}= \pm b \mp \rho \cos \alpha
\end{aligned}
$$

where the upper and lower signs stand for the curves $O_{\mathrm{g}} A$ and $O_{\mathrm{g}} B$, respectively.

In the meshing of the generating surface and a tooth being generated, the vector of the relative velocity must be perpendicular to the line normal to the generating surface at the contact point [6]. As applied to the conchoidal gears, this condition allows writing the equation of meshing as

$$
\pm b \mp \rho \cos \alpha+(x \mp a \pm \rho \sin \alpha) \cot \alpha-\varphi_{1,2} r_{\mathrm{w} 1,2}=0
$$

which represents the relationship between $\alpha$ and the angle $\varphi_{1,2}$ of rotation of the pinion/gear. Here $r_{\mathrm{w} 1,2}$ is the pitch 

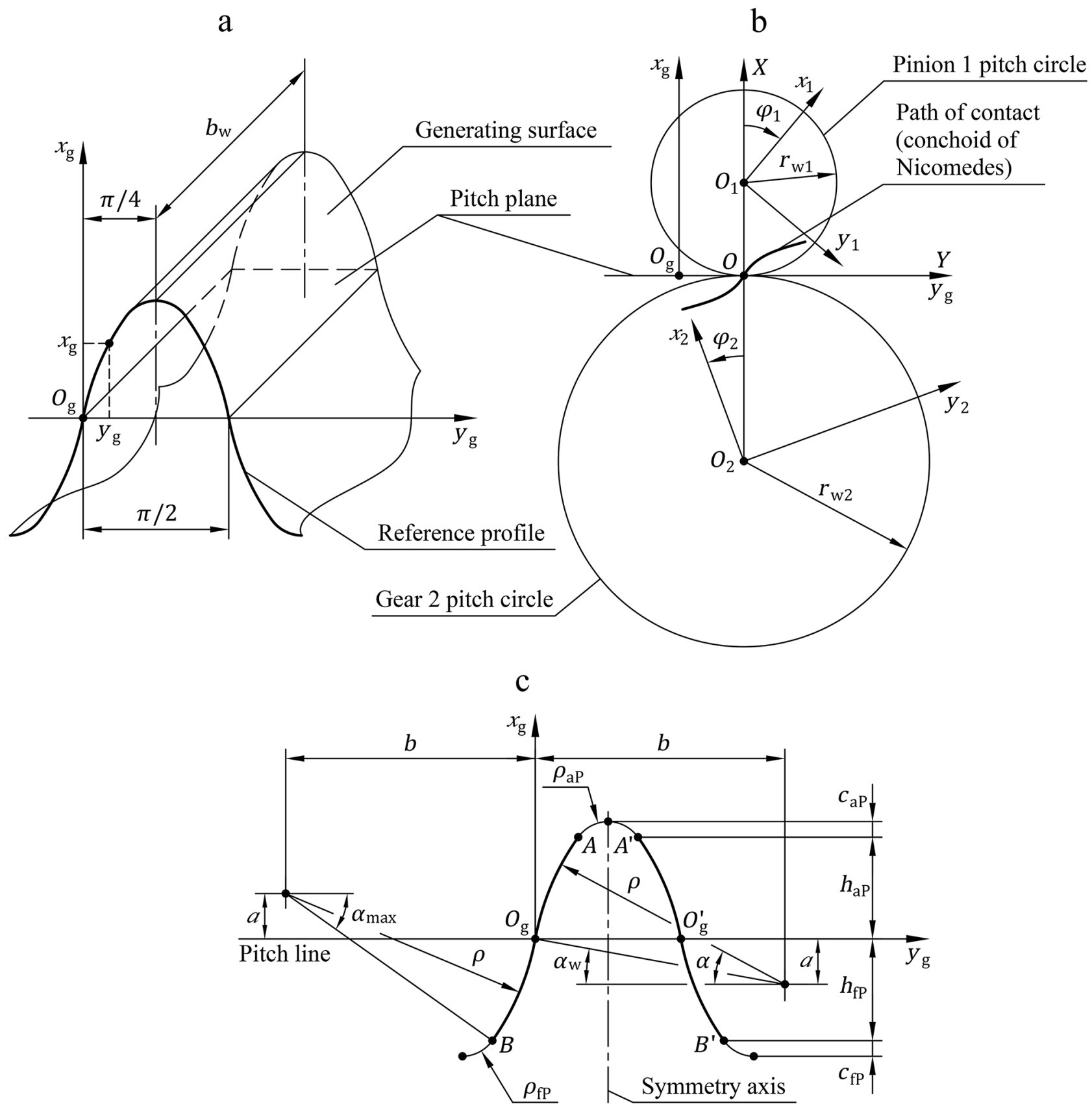

Fig. 1. Geometry of conchoidal gears: (a) generating surface; (b) pinion 1 and gear 2; (c) reference profile.

circle radius of the pinion/gear. As the pitch circles mesh without sliding, it is true that $\varphi_{1} r_{\mathrm{w} 1}=\varphi_{2} r_{\mathrm{w} 2}$.

The equation of the path of contact can be formulated in the coordinate system $X O Y$ based on equations (5) and (6) in the form

$$
\begin{aligned}
X= & x \mp a+\rho \cos (\alpha+\pi \pm \pi / 2) ; \\
Y= & (x \mp a) \tan (\alpha+\pi \pm \pi / 2) \\
& +\rho \sin (\alpha+\pi \pm \pi / 2)
\end{aligned}
$$

which coincides with the expression for the conchoid of Nicomedes with angle $(\alpha+\pi \pm \pi / 2)$ and parameters $(x \mp a)$ and $\rho$.

From equation (6) one can also derive the equations for the pinion active profiles

$$
\begin{aligned}
x_{1}= & \left(x \mp a \pm \rho \sin \alpha+r_{\mathrm{w} 1}\right) \cos \varphi_{1} \\
& +(x \mp a \pm \rho \sin \alpha) \cos \alpha \sin \varphi_{1} ; \\
y_{1}= & \left(x \mp a \pm \rho \sin \alpha+r_{\mathrm{w} 1}\right) \sin \varphi_{1} \\
& -(x \mp a \pm \rho \sin \alpha) \cot \alpha \cos \varphi_{1}
\end{aligned}
$$


Table 1. Parameters of the simulated reference profiles normalised for $m=1 \mathrm{~mm}$.

\begin{tabular}{llll}
\hline Code name & $\alpha 20$ & $\alpha 25$ & $\alpha 28$ \\
\hline${\text { Reference profile angle } \alpha_{\mathrm{w}} \text { at pitch line, }}^{\circ}$ & 19.6 & 24.85 & 27.97 \\
Maximum reference profile angle $\alpha_{\text {max }}{ }^{\circ}$ & 23 & 28 & 30.69 \\
Distance $a$ & 6.072 & 8.545 & 10.18 \\
Distance $b$ & 17.05 & 18.448 & 19.176 \\
Profile circle radius $\rho$ & 18.101 & 20.33 & 21.71 \\
Tooth addendum height $h_{\mathrm{ap}}$ & 1 & 1 & 0.9 \\
Tooth dedendum height $h_{\mathrm{fP}}$ & 1 & 1 & 0.9 \\
Tooth tip fillet radius $\rho_{\mathrm{aP}}$ & 0.4297 & 0.3266 & 0.3247 \\
Tooth root fillet radius $\rho_{\mathrm{fP}}$ & 0.4297 & 0.3266 & 0.3247 \\
Tooth tip clearance $c_{\mathrm{aP}}$ & 0.2618 & 0.1733 & 0.1589 \\
Tooth root clearance $c_{\mathrm{fP}}$ & 0.2618 & 0.1733 & 0.1589 \\
\hline
\end{tabular}
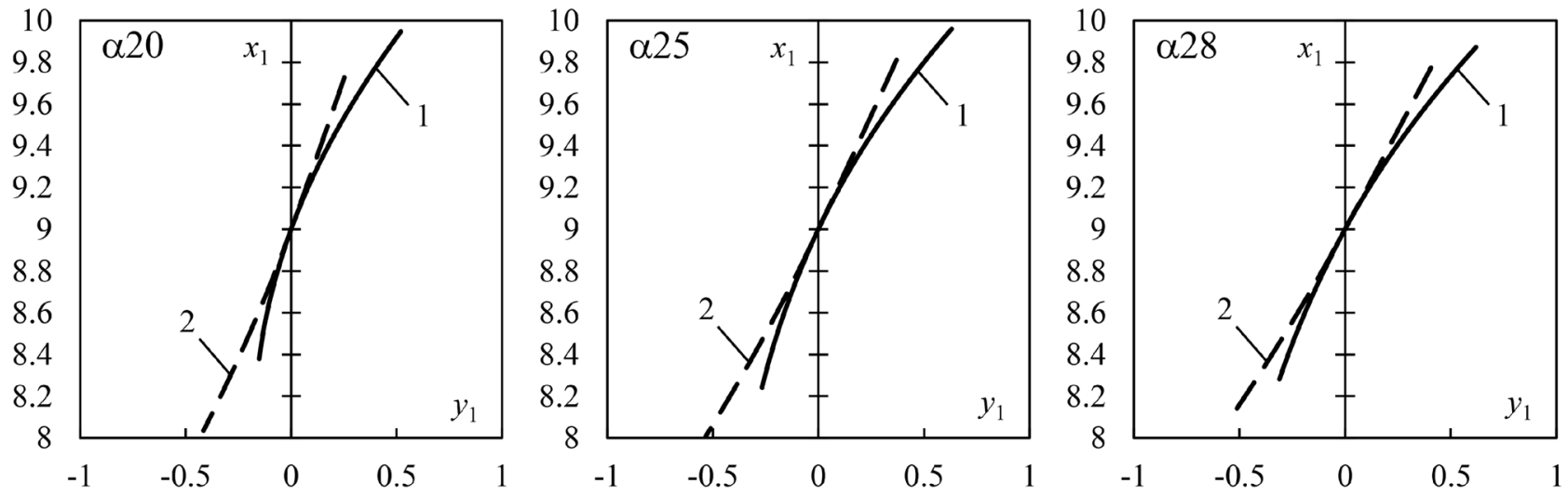

Fig. 2. Geometry of the teeth active profiles of the pinion 1 and gear 2 .

and gear active profiles

$$
\begin{aligned}
x_{2}= & \left(x \mp a \pm \rho \sin \alpha-r_{\mathrm{w} 2}\right) \cos \varphi_{2} \\
& -(x \mp a \pm \rho \sin \alpha) \cot \alpha \sin \varphi_{2} \\
y_{2}= & \left(x \mp a \pm \rho \sin \alpha-r_{\mathrm{w} 2}\right) \sin \varphi_{2} \\
& -(x \mp a \pm \rho \sin \alpha) \cot \alpha \cos \varphi_{2}
\end{aligned}
$$

in the respective coordinate systems $x_{1} O_{1} y_{1}$ and $x_{2} O_{2} y_{2}$.

Equations (6)-(8) allow thus finding the coordinates of the contact point and the points of the active profiles for specified values of $\varphi_{1}$ and $\varphi_{2}$.

Depending on the geometric parameters, the contact between teeth in a conchoidal gear pair can be of convexconcave or convex-convex type. The present study focusses on investigation of the convex-convex contact which takes place under the condition [30] that

$$
a-x \geq r_{\mathrm{w} 2} \sin ^{2} \alpha_{\max } .
$$

The following analysis requires specification of the parameters of the simulated reference profiles and gear pairs. The angle $\alpha_{\mathrm{w}}$ of $20^{\circ}$ is the most common, while it can be $25^{\circ}$ or even $28^{\circ}$ in special gear transmissions [31] (p. 75, 143). Table 1 describes three reference profiles, code-named as ' $\alpha 20$ ', ' $\alpha 25$ ' and ' $\alpha 28$ ', with $\alpha_{\mathrm{w}}$ close to the mentioned values.

Figure 2 shows the teeth profiles of the pinion 1 and gear 2 generated by the reference profiles of Table 1 . The profiles of the pinion 1 are determined due to equation (7) in the coordinate system $x_{1} O_{1} y_{1}$ (solid lines), while the profiles of the gear 2 are determined due to equation (8) in the coordinate system $x_{2} \mathrm{O}_{2} y_{2}$ (dashed lines). In both cases, the values of $\varphi_{1,2}$ are calculated by equation (6). For the sake of clarity, the profiles of the gear 2 are shown not in its own coordinate system but are meshed with the respective profiles of the pinion at $\varphi_{1}=0$. The geometry of the teeth corresponds to $u=z_{2} / z_{1}=72 / 18$ and is normalised for $m=1 \mathrm{~mm}$.

The shift of the reference profile has a significant influence on the performance of the gear pair. Table 2 presents three simulated cases: zero shift (' $\mathrm{x} 0$ '), 0.3 shift ('x0.3') and 0.5 shift (' $\mathrm{x} 0.5$ ')

Finally, Table 3 presents the parameters of the simulated gear pairs and operating conditions. Two gear pairs, code-named as ' $u 2.4$ ' and ' $u 4$ ', have the same parameters except for the number $z_{1}$ of the pinion teeth and, accordingly, gear ratio $u=z_{2} / z_{1}$. 
Table 2. Shift coefficient $x$ of the simulated reference profile normalised for $m=1 \mathrm{~mm}$.

\begin{tabular}{llll}
\hline Code name & $\mathrm{x} 0$ & $\mathrm{x} 0.3$ & $\mathrm{x} 0.5$ \\
\hline Pinion shift & 0 & +0.3 & +0.5 \\
Gear shift & 0 & -0.3 & -0.5 \\
\hline
\end{tabular}

Table 3. Parameters of the simulated gear pairs and operating conditions.

\begin{tabular}{|c|c|c|}
\hline Code name & $\mathrm{u} 2.4$ & $\mathrm{u} 4$ \\
\hline Gear ratio $u$ & 2.4 & 4 \\
\hline Number $z_{1}$ of pinion teeth & 30 & 18 \\
\hline Number $z_{2}$ of gear teeth & & \\
\hline Module $m, \mathrm{~mm}$ & & \\
\hline Effective face width $b_{\mathrm{w}}, \mathrm{mm}$ & & \\
\hline Elastic modulus $E, \mathrm{GPa}$ & & \\
\hline Brinell hardness number BHN & & \\
\hline Active profile roughness $R_{\mathrm{a}}, \mu \mathrm{m}$ & & \\
\hline Oil kinematic viscosity $v, \mathrm{~mm}^{2} / \mathrm{s}$ & & \\
\hline Pinion angular velocity $\omega_{1}, \mathrm{rad} / \mathrm{s}$ & & \\
\hline Pinion torque $T_{1}, \mathrm{Nm}$ & & \\
\hline
\end{tabular}

\subsection{Contact strength}

The instantaneous mechanical contact of two gear teeth is often treated as the contact between two cylinders with parallel axes. The relationship between the stress $\sigma_{\mathrm{H}}$ and normal force $F_{\mathrm{n}}$ in the contact zone is then defined by the Hertz equation. If the pinion and gear are made of the same steel with elastic modulus $E$, this equation takes the form [5]

$$
\sigma_{H}=0.418 \sqrt{\frac{F_{\mathrm{n}} E}{b_{\mathrm{w}} R_{\mathrm{r}}}}
$$

where $R_{\mathrm{r}}$ is the reduced curvature radius of the active profiles of the mating teeth at the contact point; $b_{\mathrm{w}}$ is the effective face width.

For the conchoidal gear pair, it yields from equations (5)-(8) that

\section{See equation below.}

On the other hand, following the study [28], one can derive a similar expression for the involute gear pair:

$$
R_{\mathrm{rinv}}=\frac{\left(r_{\mathrm{w} 1} \sin ^{2} \alpha_{\mathrm{w}}+x+x_{\mathrm{g}}\right)\left(r_{\mathrm{w} 2} \sin ^{2} \alpha_{\mathrm{w}}-x-x_{\mathrm{g}}\right)}{\left(r_{\mathrm{w} 1}+r_{\mathrm{w} 2}\right) \sin ^{3} \alpha_{\mathrm{w}}} .
$$

The normal force $F_{\mathrm{n}}$ in the contact zone is expressed via the pinion torque $T_{1}$ as

$$
F_{\mathrm{n}}=\frac{k T_{1}}{r_{\mathrm{w} 1} \cos \alpha}
$$

where $k=1$ for one-pair contact and $k=0.5$ for doubletooth contact.

Substitution of equation (10) into equation (9) leads to the equation

$$
\sigma_{H}=\frac{0.418}{\theta} \sqrt{\frac{k T_{1} E}{b_{\mathrm{w}} r_{\mathrm{w} 1}}}
$$

where the coefficient $\theta$ given by

$$
\theta=\sqrt{R_{\mathrm{r}} \cos \alpha}
$$

depends solely on the geometry of the active profiles. According to equation (11), $\theta$ is inverse proportional to $\sigma_{\mathrm{H}}$ and, thereby, can serve as the measure of contact strength.

Based on the expressions of $R_{\mathrm{r}}$ con and $R_{\mathrm{r} \text { inv }}$ above, one easily finds $\theta$ for the conchoidal gear pair:

$$
\text { See equation (12) below. }
$$

and for the involute gear pair:

$$
\begin{aligned}
\theta_{\text {inv }}^{2} & =R_{\mathrm{r} \text { inv }} \cos \alpha_{\mathrm{w}} \\
& =\frac{\left(r_{\mathrm{w} 1} \sin ^{2} \alpha_{\mathrm{w}}+x+x_{\mathrm{g}}\right)\left(r_{\mathrm{w} 2} \sin ^{2} \alpha_{\mathrm{w}}-x-x_{\mathrm{g}}\right) \cos \alpha_{\mathrm{w}}}{\left(r_{\mathrm{w} 1}+r_{\mathrm{w} 2}\right) \sin ^{3} \alpha_{\mathrm{w}}} .
\end{aligned}
$$

Note that $\theta_{\text {con }}$ of equation (12) is a function of $\alpha$, while $\theta_{\text {inv }}$ of equation (13) is a function of $x_{\mathrm{g}}$.

Figure 3 illustrates the variation ranges of the ratio $\theta_{\text {con }} / \theta_{\text {inv }}$ calculated by equations (12) and (13) for the reference profiles and gear pairs specified in Tables $1-3$. The limit values of each variation range correspond to the limit points of the path of contact. It is seen that for all

$$
\begin{array}{r}
R_{\mathrm{r} \text { con }}=\frac{\left(r_{\mathrm{w} 1} \frac{\sin ^{3} \alpha}{\sin \alpha_{\mathrm{w}}}+x \mp a \pm \rho \sin \alpha\right)\left(r_{\mathrm{w} 2} \frac{\sin ^{3} \alpha}{\sin \alpha_{\mathrm{w}}}-x \pm a \mp \rho \sin \alpha\right)}{\left(r_{\mathrm{w} 1}+r_{\mathrm{w} 2}\right) \sin \alpha_{\mathrm{w}}} . \\
\theta_{\text {con }}^{2}=R_{\mathrm{r} \operatorname{con}} \cos \alpha=\frac{\left(r_{\mathrm{w} 1} \frac{\sin ^{3} \alpha}{\sin \alpha_{\mathrm{w}}}+x \mp a \pm \rho \sin \alpha\right)\left(r_{\mathrm{w} 2} \frac{\sin ^{3} \alpha}{\sin \alpha_{\mathrm{w}}}-x \pm a \mp \rho \sin \alpha\right) \cos \alpha}{\left(r_{\mathrm{w} 1}+r_{\mathrm{w} 2}\right) \sin \alpha_{\mathrm{w}}}
\end{array}
$$




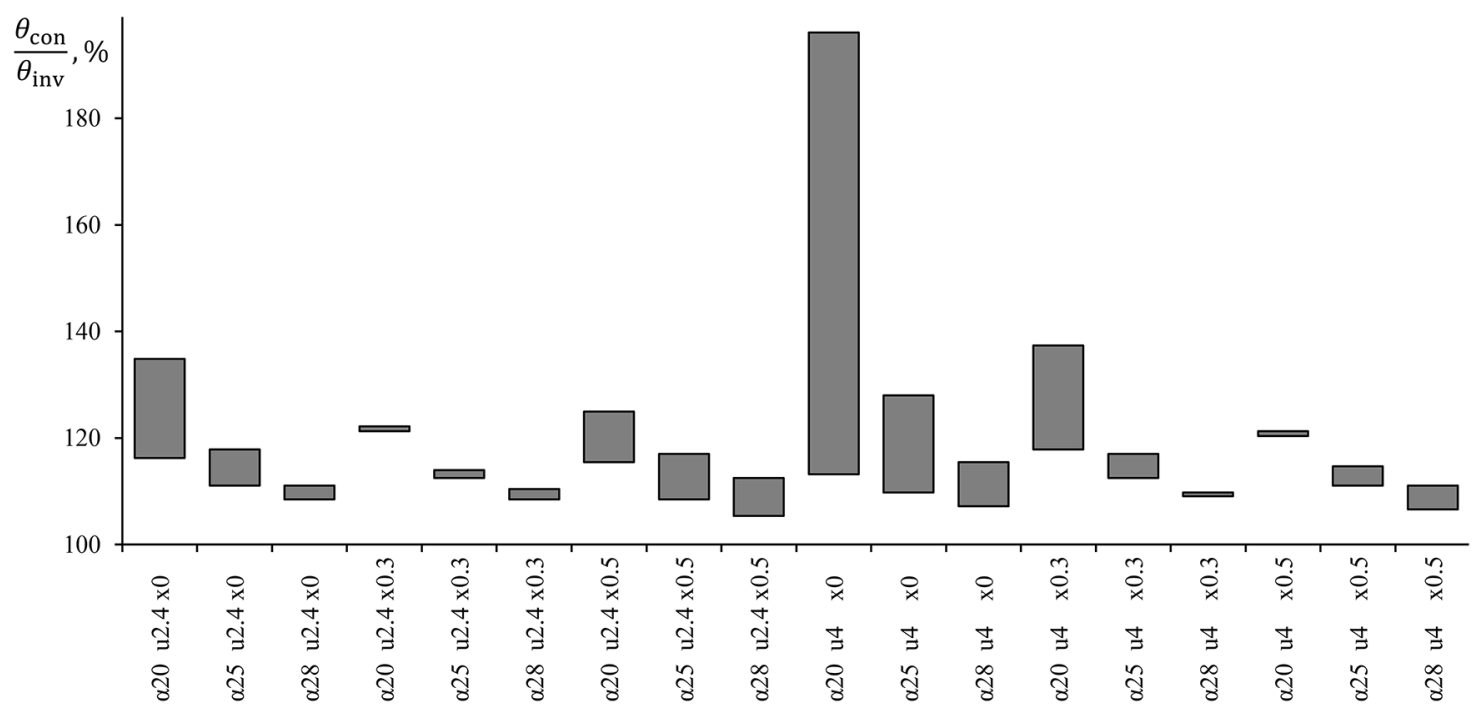

Fig. 3. Ratio between contact strength coefficients $\theta_{\text {con }}$ and $\theta_{\text {inv }}$.

combinations under consideration, $\theta_{\text {con }} / \theta_{\text {inv }}$ is noticeably larger than $100 \%$. The lower limit of $\theta_{\text {con }} / \theta_{\text {inv }}$ varies between $105 \%$ and $121 \%$, implying that the conchoidal gear pairs have $5-21 \%$ higher contact strength compared to the involute gear pairs of the same configuration. An exceptional case is ' $\alpha 20 \mathrm{u} 4 \mathrm{x} 0$ ', implying $\alpha_{\mathrm{w}}=20^{\circ}, u=4$ and $x=0$, at which the upper limit of $\theta_{\text {con }} / \theta_{\text {inv }}$ is about $200 \%$. This case is characterised by a close to zero curvature radius at the tooth dedendum of the pinion and, therefore, is eliminated from consideration. It is notable that $\theta_{\text {con }} / \theta_{\text {inv }}$ decreases substantially as $\alpha_{\mathrm{w}}$ increases.

\subsection{Energy efficiency}

The active profiles of the mating teeth slide relative each other at the contact point with velocity $v_{\mathrm{g}}$. This is inevitably accompanied by the friction process which is characterised by friction coefficient $\mu$. Introduce the energy efficiency of a gear pair as follows:

$$
\eta=1-\frac{z_{1}}{2 \pi T_{1} \omega_{1}} \int_{\varphi_{11}}^{\varphi_{12}} \mu F_{\mathrm{n}} v_{\mathrm{g}} d \varphi
$$

where $\omega_{1}$ is the angular velocity of the pinion; $\varphi_{11}$ and $\varphi_{12}$ are the angles of the pinion rotation which correspond to the start and end of the meshing phase. The start contact point and end contact point in the meshing of the pinion and gear are defined in the generating process by the points of the reference profile with angle $\alpha_{\max 1}$ at $\varphi_{1}=\varphi_{11}$ and angle $\alpha_{\max 2}$ at $\varphi_{1}=\varphi_{12}$, respectively. The values of $\alpha_{\max 1}$ and $\alpha_{\max 2}$ are found by the equations below:

See equation below.
The integral term in equation (14) indicates the fraction of the input power that transforms into friction heat over one meshing phase from $\varphi_{11}$ to $\varphi_{12}$.

For the conchoidal gear pair, the sliding velocity is derived from equations (5) and (6) as

$$
v_{\mathrm{g} \text { con }}=\omega_{1} \frac{u+1}{u} \frac{x \pm \rho\left(\sin \alpha-\sin \alpha_{\mathrm{w}}\right)}{\sin \alpha}
$$

while for the involute gear pair, it can be expressed in our notation as

$$
v_{\mathrm{ginv}}=\omega_{1} \frac{u+1}{u} \frac{x+x_{\mathrm{g}}}{\sin \alpha_{\mathrm{w}}} .
$$

For steel-on-steel gear teeth contacts, the friction coefficient $\mu$ is well approximated by the empirical function $[32,33]$

$$
\mu=0.09\left(10+\lg \left(\frac{\mathrm{BHN} \mathrm{R}_{\mathrm{a}}}{E R_{\mathrm{r}}}\right)\right) \frac{\left(F_{\mathrm{n}} / b_{\mathrm{w}}\right)^{0.1}}{v^{0.07} v_{\Sigma}^{0.1} v_{g}^{0.35} R_{\mathrm{r}}^{0.25}}
$$

where BHN is the Brinell hardness number; $R_{\mathrm{a}}$ is the roughness parameter; $v$ is the oil kinematic viscosity; $v_{\Sigma}$ is the sum of the velocity components of the active profiles at the contact point perpendicular to the line of contact [31] (p. 182). The quantities in equation (15) should be specified in the following units of measurements: BHN and $E$ in the same units; $F_{\mathrm{n}}$ in $\mathrm{N} ; b_{\mathrm{w}}$ in $\mathrm{mm} ; R_{\mathrm{r}}$ and $R_{\mathrm{a}}$ in $\mathrm{cm} ; v$ in $\mathrm{mm}^{2} / \mathrm{s}$; $v_{\mathrm{g}}$ and $v_{\Sigma}$ in $\mathrm{cm} / \mathrm{s}$.

$$
\begin{aligned}
& \left(r_{\mathrm{w} 1}+h_{\mathrm{aP}}\right)^{2}=\left(r_{\mathrm{w} 1}+\rho \sin \alpha_{\max 1}-a+x\right)^{2}+\left(\rho \sin \alpha_{\max 1}-a+x\right)^{2} \cot ^{2} \alpha_{\max 1} \\
& \left(r_{\mathrm{w} 2}+h_{\mathrm{fP}}\right)^{2}=\left(r_{\mathrm{w} 2}+\rho \sin \alpha_{\max 2}-a-x\right)^{2}+\left(\rho \sin \alpha_{\max 2}-a+x\right)^{2} \cot ^{2} \alpha_{\max 2}
\end{aligned}
$$




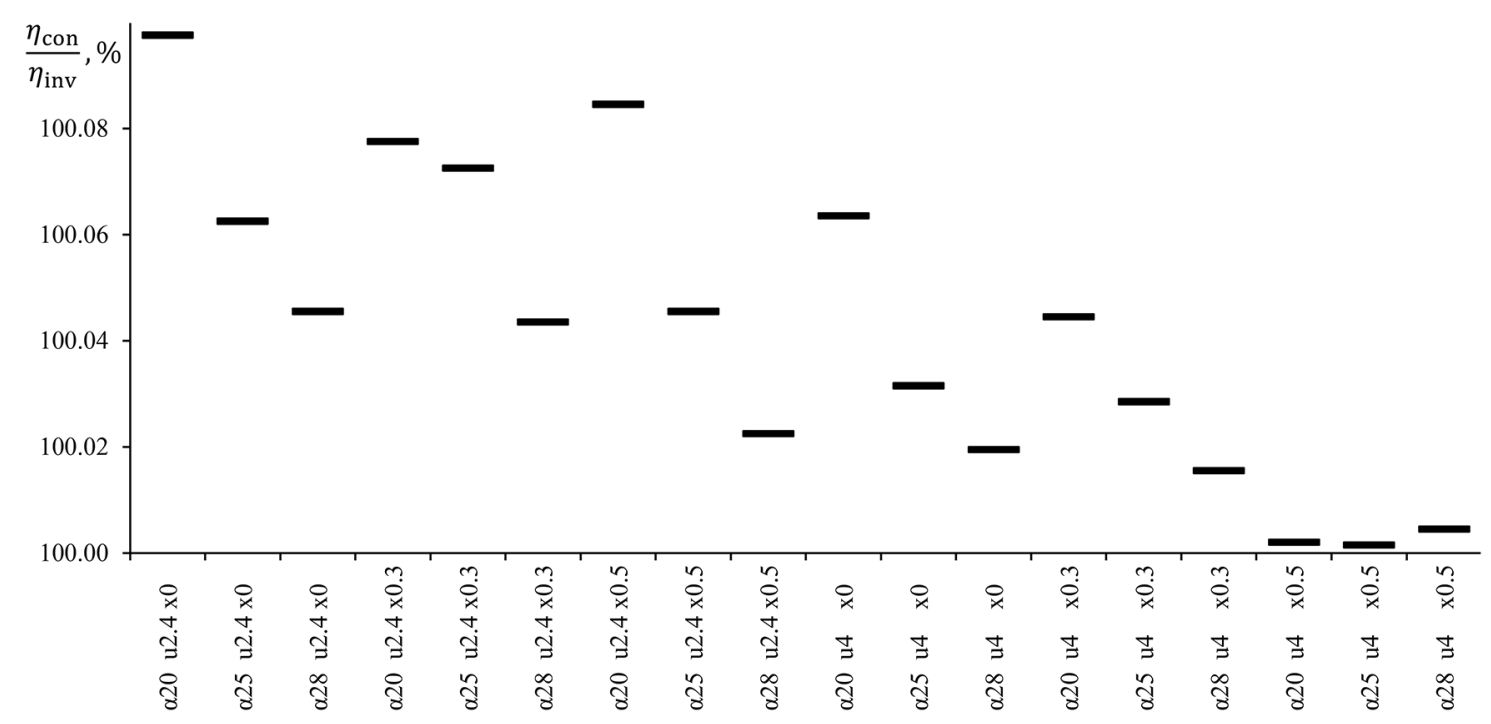

Fig. 4. Ratio between energy efficiencies $\eta_{\text {con }}$ and $\eta_{\text {inv }}$.

The formula to calculate $v_{\Sigma}$ for the conchoidal gear pair is obtained from equations (5) and (6) in the form

$$
v_{\Sigma \text { con }}=\omega_{1}\left(\frac{u-1}{u} \frac{\rho\left(\sin \alpha-\sin \alpha_{\mathrm{w}}\right) \pm x}{\sin \alpha} \mp \frac{2 r_{\mathrm{w} 1} \rho \sin ^{2} \alpha}{\rho \sin \alpha_{\mathrm{w}}+x}\right)
$$

while for the involute gear pair, it reads

$$
v_{\Sigma \text { inv }}=\omega_{1}\left(\frac{u-1}{u} \frac{x_{g}+x}{\sin \alpha_{\mathrm{w}}}+2 r_{\mathrm{w} 1} \sin \alpha_{\mathrm{w}}\right) .
$$

Figure 4 shows the values of the ratio between the energy efficiencies $\eta_{\text {con }}$ and $\eta_{\text {inv }}$ calculated by equation (14) for the respective conchoidal and involute gear pairs. It is seen that $\eta_{\text {con }}$ is up to $0.1 \%$ larger than $\eta_{\text {inv }}$ for all considered combinations, suggesting that the conchoidal gear pairs have similar energy efficiency as the involute gear pairs of the same configuration. This result is explained by the fact that $\mu$ of equation (15) takes a smaller value in the case of conchoidal gear pair, which is due to the inequalities $v_{\Sigma \text { con }}>v_{\Sigma \text { inv }}$ and $R_{\text {r con }}>R_{\text {rinv }}$.

\section{Experimental study}

The foregoing theoretical analysis showed that the conchoidal gear pairs have a substantially higher contact strength and similar energy efficiency if compared to the involute gear pairs with the same parameters. These findings should undergo experimental validation to be accepted. This section describes an experimental study of the conchoidal and involute gear pairs in terms of the mentioned characteristics.

\subsection{Tooth-cutting tool}

A hob cutter was designed and manufactured for cutting conchoidal gear pairs. It was made of P18 steel due to
Table 4. Hob cutter parameters.

\begin{tabular}{ll}
\hline Parameter & Value \\
\hline Module $m, \mathrm{~mm}$ & 1.95 \\
Number of threads & 1 \\
Number of teeth & 12 \\
Normal pitch, mm & 6.126 \\
Axial pitch, mm & 6.128 \\
Reference diameter, mm & 84.086 \\
Lead angle, & \\
\hline
\end{tabular}

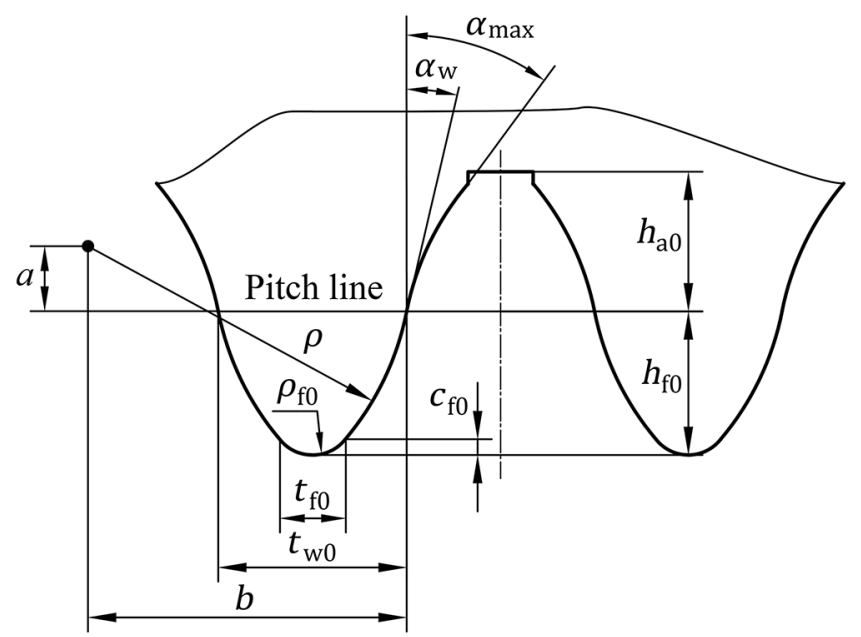

Fig. 5. Hob cutter tooth profile.

GOST 19265-73 (EN X75WCrV18-4-1) and heat treated to Rockwell hardness HRC 65. The parameters of the hob cutter are presented in Table 4, while its tooth profile is schematically shown in Figure 5. The parameters of the 
Table 5. Reference profile parameters.

\begin{tabular}{lll}
\hline Parameter & Formula & Value \\
\hline Module $m, \mathrm{~mm}$ & & 1.95 \\
Backlash $\delta, \mathrm{mm}$ & & 0.2 \\
Reference profile angle $\alpha_{\mathrm{w}}$ at pitch line, & & 19.6 \\
Maximum reference profile angle $\alpha_{\mathrm{max}}{ }^{\circ}$ & & 23 \\
Distance $a, \mathrm{~mm}$ & $a=6.072 m$ & 11.84 \\
Distance $b, \mathrm{~mm}$ & $b=17.05 m$ & 33.248 \\
Profile circle radius $\rho, \mathrm{mm}$ & $\rho=18.101 m$ & 35.297 \\
Tooth thickness $t_{\mathrm{w} 0}$ at pitch line, mm & $t_{\mathrm{w} 0}=\pi m / 2+\delta$ & 3.263 \\
Tooth thickness $t_{\mathrm{f} 0}$ at height $\left(h_{\mathrm{f} 0}-c_{\mathrm{f} 0}\right), \mathrm{mm}$ & $t_{\mathrm{f} 0}=0.791 m$ & 1.542 \\
& & \\
Tooth root fillet $\rho_{\mathrm{f} 0}, \mathrm{~mm}$ & $\rho_{\mathrm{f} 0}=\frac{t_{\mathrm{f} 0}+\delta}{2 \cos \alpha_{\max }}$ & 0.946 \\
Tooth root clearance $c_{\mathrm{f} 0}, \mathrm{~mm}$ & $c_{\mathrm{f} 0}=\rho_{\mathrm{f} 0}\left(1-\sin \alpha_{\max }\right)$ & 0.576 \\
Tooth dedendum height $h_{\mathrm{f} 0}, \mathrm{~mm}$ & $h_{\mathrm{f} 0}=m+c_{\mathrm{f} 0}$ & 2.526 \\
Tooth addendum height $h_{\mathrm{a} 0}, \mathrm{~mm}$ & $h_{\mathrm{a} 0}=h_{\mathrm{f} 0}$ & 2.526 \\
\hline
\end{tabular}

reference profile were calculated using the formulae given in Table 5.

\subsection{Tested gear pairs}

Using the hob cutter, 3 conchoidal gear pairs were manufactured. Further 3 involute gear pairs were manufactured using a standard hob cutter of the same module. All gears were cut out of $40 \mathrm{X}$ steel (EN $41 \mathrm{Cr} 4)$ due to GOST 4543-71 364. Table 6 presents its mechanical properties. The conchoidal and involute gear pairs had the same configuration presented in Table 7 . Note that they were manufactured with the reference profile shift corresponding to ' $\mathrm{x} 0.5$ ' (see Tab. 2).

The pinion and gear of the tested gear pair (conchoidal or involute) were installed on the shafts supported by bearings inside a gear box. An oil bath lubrication method with natural convection was used. The gears were lubricated by an AK15 motor oil. The level of oil in the gear box was regularly monitored.

\subsection{Gear test rig}

The tests were carried out using a gear test rig shown in Figure 6 . The principal units of the test rig were an electric motor, the gear box with the tested gear pair inside and an electromagnetic powder brake. The motor of rated power $15 \mathrm{~kW}$ applied torque $T_{1}$ to the pinion shaft and drove it with angular velocity $\omega_{1}$ of $153.9 \mathrm{rad} / \mathrm{s}$. The brake allowed controlling the torque $T_{2}$ at the gear shaft by measuring displacements of an elastic element. The motor, gear box and brake were dead mounted to a massive basement with bolts. The shafts of the mentioned units were connected by flexible couplings. An accurate alignment of the shafts was provided. The measurement system of the test rig allowed measuring the active power $P=T_{1} \omega_{1}$ of the motor, the gear torque $T_{2}$ and the temperature $\vartheta$ of the oil in the gear box.
Table 6. Gear steel mechanical properties.

\begin{tabular}{ll}
\hline Property & Value \\
\hline Elastic modulus $E, \mathrm{GPa}$ & 210 \\
Brinell hardness number BHN & 270 \\
Fatigue contact stress $\sigma_{\mathrm{H} \mathrm{lim}}, \mathrm{MPa}$ & 610 \\
Allowable contact stress $\left[\sigma_{\mathrm{H}}\right], \mathrm{MPa}$ & 483 \\
Base number $N_{\mathrm{H} \text { lim } \text { of cycles }}$ & $2 \cdot 10^{7}$ \\
\hline
\end{tabular}

Table 7. Gear pair parameters.

\begin{tabular}{ll}
\hline Parameter & Value \\
\hline Module $m, \mathrm{~mm}$ & 1.95 \\
Number $z_{1}$ of pinion teeth & 14 \\
Number $z_{2}$ of gear teeth & 88 \\
Gear ratio $u$ & 6.29 \\
Reference profile shift coefficient $x$ & 0.5 \\
Pinion pitch circle radius $r_{\mathrm{w} 1}, \mathrm{~mm}$ & 13.65 \\
Gear pitch circle radius $r_{\mathrm{w} 2}, \mathrm{~mm}$ & 85.8 \\
Effective face width $b_{\mathrm{w}}, \mathrm{mm}$ & 60 \\
Active profile roughness $R_{\mathrm{a}}, \mu \mathrm{m}$ & 3.2 \\
Oil kinematic viscosity $v, \mathrm{~mm}^{2} / \mathrm{s}$ & 15 \\
\hline
\end{tabular}

\subsection{Research methodology}

Each gear pair was tested according to a multi-step procedure developed in the Central Scientific Research Institute of Machine Building and Metalworking (former Soviet Union) intended for conventional gear transmissions, as described in Table 8. 


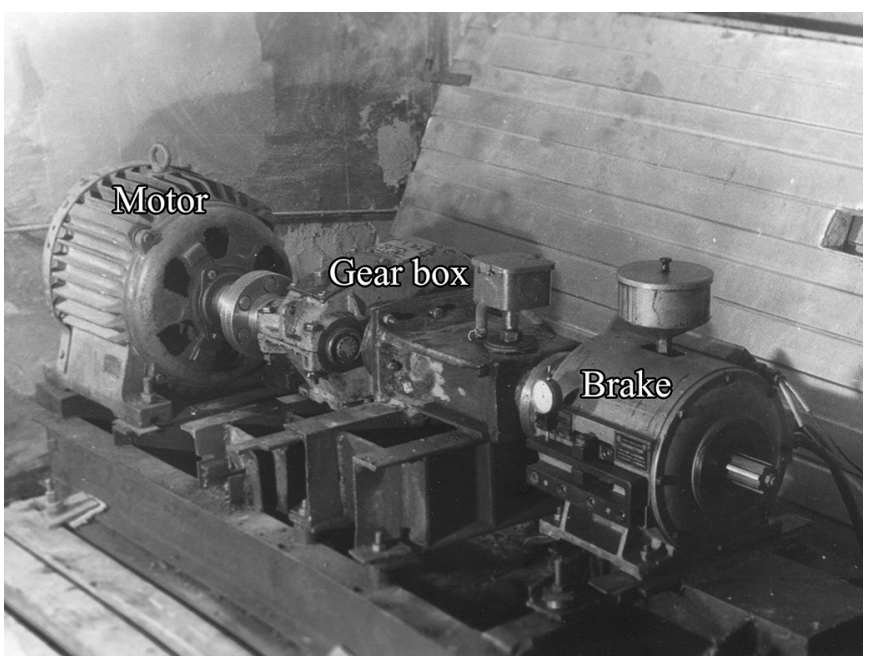

Fig. 6. Gear test rig.

Table 8. Experimental multi-step procedure.

\begin{tabular}{lll}
\hline $\begin{array}{l}\text { Loading } \\
\text { step }\end{array}$ & Pinion torque $T_{1}$ & Total duration \\
\hline 0 & idle mode & 2 hours \\
1 & $0.2\left[T_{1}\right]=6.2 \mathrm{Nm}$ & 24 hours \\
2 & $0.4\left[T_{1}\right]=12.4 \mathrm{Nm}$ & 24 hours \\
3 & $0.6\left[T_{1}\right]=18.6 \mathrm{Nm}$ & 24 hours \\
4 & $0.8\left[T_{1}\right]=24.8 \mathrm{Nm}$ & 24 hours \\
5 & $1.0\left[T_{1}\right]=31 \mathrm{Nm}$ & $1.0 \mathrm{~N}_{\mathrm{H} \mathrm{lim}}=2 \cdot 10^{7}$ cycles \\
6 & $1.2\left[T_{1}\right]=37.2 \mathrm{Nm}$ & $1.5 \mathrm{~N}_{\mathrm{H} \mathrm{lim}}=3 \cdot 10^{7}$ cycles \\
\hline
\end{tabular}

Zero step was a 2-hour running-in of the gear pair with the brake off (idle mode). At each next loading step, the gear torque $T_{2}$ was increased so that the corresponding pinion torque $T_{1}$ increased by $0.2\left[T_{1}\right]$, where $\left[T_{1}\right]$ is the allowable pinion torque. The value of $\left[T_{1}\right]$ was determined based on equation (9) with account of different factors:

$$
\left[T_{1}\right]=\frac{1}{K_{\mathrm{H} \alpha} K_{\mathrm{H} \beta} K_{\mathrm{HV}} Z_{\mathrm{H}}^{2} Z_{\varepsilon}^{2}} \frac{b_{\mathrm{w}} r_{\mathrm{w} 1}^{2}}{500 \mathrm{Z}_{\mathrm{E}}^{2}} \frac{u}{u+1}\left[\sigma_{\mathrm{H}}\right]
$$

where $\left[\sigma_{\mathrm{H}}\right]$ is the allowable contact stress (see Tab. 6); $K_{\mathrm{H} \alpha}$ is the factor of non-uniform load distribution between the teeth; $K_{\mathrm{H} \beta}$ is the factor of non-uniform load distribution along the contact lines; $K_{\mathrm{HV}}$ is the factor of the internal dynamic load in the meshing; $Z_{\mathrm{E}}$ is the factor in view of the mechanical properties of the gears, $\sqrt{\mathrm{MPa}} ; Z_{\mathrm{H}}$ is the factor in view of the shape of the mating teeth surfaces at the pitch point; $Z_{\varepsilon}$ is the factor in view of the total length of the contact lines. In the equation above, $\left[T_{1}\right]$ is in $\mathrm{Nm},\left[\sigma_{\mathrm{H}}\right]$ is in $\mathrm{MPa}, b_{\mathrm{w}}$ and $r_{\mathrm{w} 1}$ are in $\mathrm{mm}$.

At the loading steps 1 to 4 , the gear pair was tested for 8 hours per day, with total duration of 24 hours. Accordingly, the state of the active surfaces of the gears was examined after each 8 test hours. After the loading step 4, the used oil

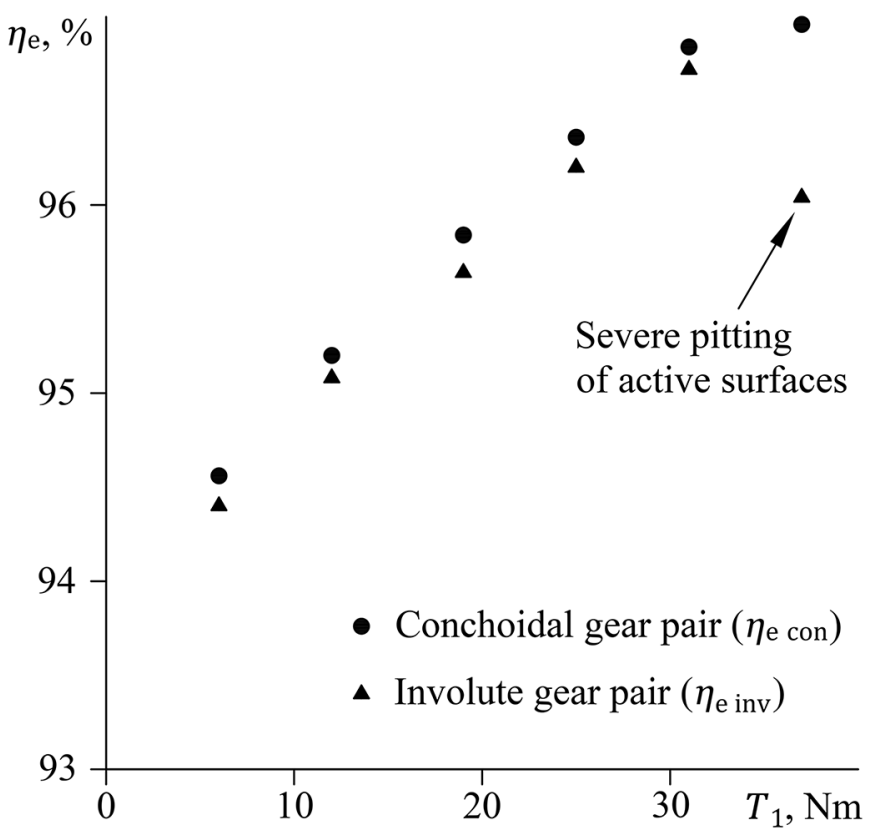

Fig. 7. Gear test rig energy efficiency $\eta_{\mathrm{e}}$ vs pinion torque $T_{1}$.

was drained from the gear box, the gear box and the components inside it were cleaned, and fresh oil was added. At the loading steps 5 and 6 with respective loads $\left[T_{1}\right]$ and $1.2\left[T_{1}\right]$, the gear pair was tested for 8 hours per day, with total number of pinion cycles of $N_{\mathrm{H}} \lim$ and $1.5 N_{\mathrm{H}} \lim$, respectively. Here $N_{\mathrm{H}} \lim$ is the base number of cycles (see Tab. 6).

The energy efficiency $\eta_{\mathrm{e}}$ of the test rig was determined from the known values of the motor active power $P$, pinion angular velocity $\omega_{1}$ and gear torque $T_{2}$ as follows:

$$
\eta_{e}=\frac{T_{2}}{T_{1} u}=\frac{T_{2} \omega_{1}}{P u} .
$$

It is noteworthy that $\eta_{\mathrm{e}}$ represents the product of the energy efficiencies of all units of the test rig, including the gear box. Since the test rig operated under the same kinematic and loading conditions regardless of gear pair type, one can compare the energy efficiencies of the conchoidal and involute gear pairs based on the ratio between the values of $\eta_{\mathrm{e} \text { con }}$ and $\eta_{\mathrm{e} \text { inv }}$ obtained by testing the respective conchoidal and involute gear pairs.

\section{Results and discussion}

The experimental data are shown in Figures 7 and 8. Each point indicates the average stationary value obtained from testing 3 gear pairs at a specific loading step.

Figure 7 shows the dependence of the energy efficiencies $\eta_{\mathrm{econ}}$ and $\eta_{\mathrm{einv}}$ on the pinion torque $T_{1}$. It is seen that $\eta_{\mathrm{econ}}$ is systematically $0.1-0.2 \%$ larger than $\eta_{\mathrm{e} \text { inv }}$, implying that the conchoidal gear pair is slightly more energy efficient than the involute one. The value of $\eta_{\mathrm{e} \text { inv }}$ at $T_{1}=37.2 \mathrm{Nm}$, however, is not in line with the general trend. An after-test 


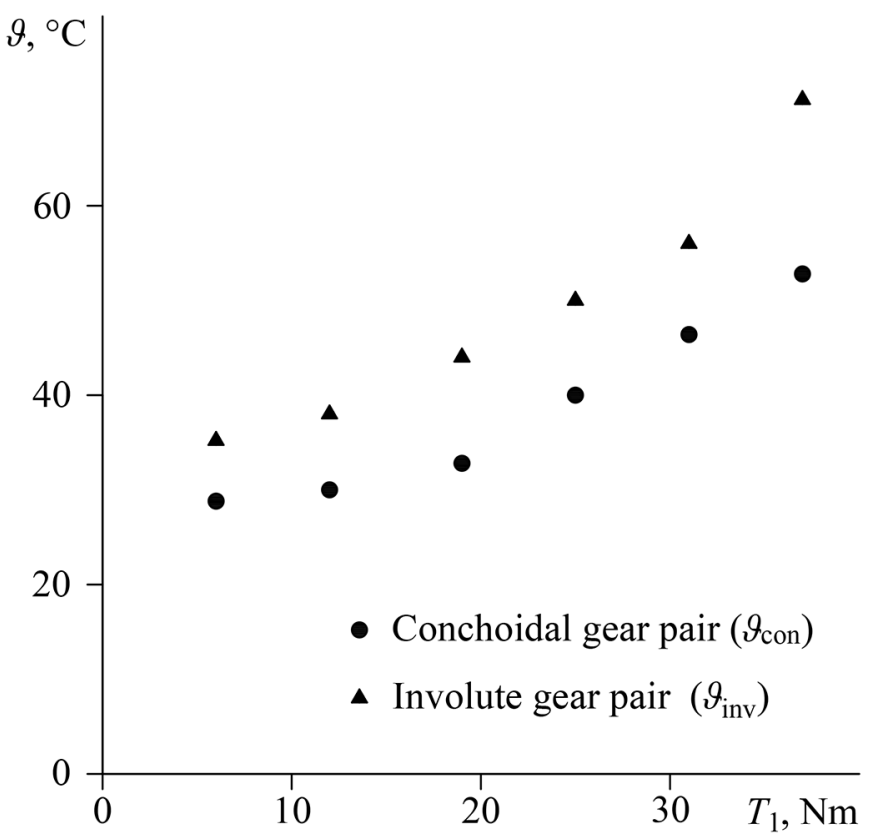

Fig. 8. Gear box oil temperature $\vartheta$ vs pinion torque $T_{1}$.

visual examination showed that the active surfaces of the involute gears were subjected to severe pitting, whereas the conchoidal gears were damaged insignificantly. This allows to explain the unexpected decrease in $\eta_{\mathrm{einv}}$ at $T_{1}=37.2 \mathrm{Nm}$.

The data presented in Figure 7 suggest that $T_{1}$ of about $31 \mathrm{Nm}$ corresponds to the load capacity of the involute gear pair. On the other hand, the stable growth of $\eta_{\mathrm{econ}}$ allows stating that the load capacity of the conchoidal gear pair is as minimum as $37.2 \mathrm{Nm}$, which is $20 \%$ larger. This correlates well with the theoretical finding that the conchoidal gear pairs have $5-21 \%$ higher contact strength compared to the involute gear pairs of the same configuration.

Figure 8 shows the influences of $T_{1}$ on the gear box oil temperatures $\vartheta_{\text {con }}$ and $\vartheta_{\text {inv }}$ measured for the respective conchoidal and involute gear pairs. According to the presented values, $\vartheta_{\text {inv }}$ is substantially larger than $\vartheta_{\text {con }}$, i.e., the involute gear pair generates more friction heat than the conchoidal one. This confirms qualitatively the results of Figure 7. It is also seen that the increase in $\vartheta_{\text {inv }}$ is large at $T_{1}=37.2 \mathrm{Nm}$, which is in agreement with the behaviour of $\eta_{\text {einv }}$.

For the nominal mode of $T_{1}=31 \mathrm{Nm}, \vartheta_{\text {con }}$ is $17 \%$ smaller than $\vartheta_{\text {inv }}$ (see Fig. 8). For the sake of comparison, flash temperatures arising in the contact points of the tested gear pairs operating in the nominal mode were simulated based on Blok's formula [5]. The simulations show that as compared to the involute gear pair, the flash temperature in the conchoidal gear pair is $27 \%$ lower for the pinion tooth addendum on gear tooth dedendum contact, $56 \%$ lower for the pinion tooth dedendum on gear tooth addendum contact, and on average $20 \%$ higher for the teeth contact in the vicinity of the pitch point which is about $0.4 m$ in height.

\section{Conclusion}

The conchoidal path-of-contact spur gears of convexconvex contact type were systematically investigated regarding their load capacity and energy efficiency. The theoretical analysis conducted for different values of the reference profile parameters and gear ratio showed that the conchoidal gear pairs are $5-21 \%$ stronger in terms of contact stress and have similar energy efficiency if compared to the traditional involute gear pairs of the same configuration. These findings were experimentally validated using a gear test rig in which the energy efficiency was determined by measuring the active power of the motor driving the pinion shaft for a controlled value of the torque at the gear shaft. The load capacity of the tested gear pair was estimated by analysing the behaviour of the energy efficiency under intensifying loading conditions. It was found that the load capacity of the conchoidal gear pair is higher by more than $20 \%$, while its energy efficiency is slightly higher. A good agreement between the obtained theoretical and experimental results confirms a substantially higher load capacity of the conchoidal gears.

This research did not receive any specific grant from funding agencies in the public, commercial, or not-forprofit sectors.

\section{Notation}

a Geometric parameter

$b \quad$ Geometric parameter

$b_{\mathrm{w}} \quad$ Effective face width

$c_{\mathrm{a}} \quad$ Tooth tip clearance

$c_{\mathrm{f}} \quad$ Tooth root clearance

$h_{\mathrm{a}} \quad$ Tooth addendum height

$h_{\mathrm{f}} \quad$ Tooth dedendum height

$m \quad$ Module

$r_{\mathrm{w}} \quad$ Pitch circle radius

$u \quad$ Gear ratio

$v_{\mathrm{g}} \quad$ Sliding velocity

$x \quad$ Reference profile shift coefficient

$x_{\mathrm{g}} O_{\mathrm{g}} y_{\mathrm{g}}$ Coordinate system aligned with reference profile

$z \quad$ Number of teeth

$E \quad$ Elastic modulus

$F_{\mathrm{n}} \quad$ Normal force

$N_{\mathrm{H} \lim }$ Base number of cycles

$P \quad$ Motor active power

$R_{\mathrm{a}} \quad$ Roughness parameter

$R_{\mathrm{r}} \quad$ Reduced curvature radius

$T \quad$ Torque

$\left[T_{1}\right] \quad$ Allowable pinion torque

$X O Y \quad$ Fixed coordinate system

$\alpha \quad$ Reference profile angle

$\alpha_{\mathrm{w}} \quad$ Reference profile angle at pitch line

$\alpha_{\max } \quad$ Maximum reference profile angle

$\eta \quad$ Simulated energy efficiency of gear pair

$\eta_{\mathrm{e}} \quad$ Measured energy efficiency of gear test rig

$\theta \quad$ Contact strength coefficient

$\vartheta \quad$ Oil temperature

$\mu \quad$ Friction coefficient

$v \quad$ Oil kinematic viscosity 
$\rho$

$\rho_{\mathrm{a}}$

$\rho_{\mathrm{f}}$

$\sigma_{\mathrm{H}}$

$\left[\sigma_{\mathrm{H}}\right]$

$\varphi$

$\omega_{1}$

$\mathrm{BHN}$

$\mathrm{p}$

0

1

2

1,2

con

inv

\section{References}

[1] E. Wildhaber, Helical gearing, patent US 1601750, 1926

[2] M.L. Novikov, Gear transmissions and cam mechanisms with a point meshing system, patent SU109113, 1956 (in Russian)

[3] F.L. Litvin, C.B. Tsay, Helical gears with circular arc teeth: simulation of conditions of meshing and bearing contact, J. Mech. Trans. Autom. 107, 556-564 (1985)

[4] A. Dyson, H.P. Evans, R.W. Snidle, Wildhaber-Novikov circular arc gears: geometry and kinematics, Proc. R. Soc. A 403, 313-340 (1986)

[5] V.N. Kudrjavcev, J.A. Derzhavec, E.G. Gluharev, Design and calculation of reduction gears, Mashinostroenie, Leningrad, 1971 (in Russian)

[6] F.L. Litvin, J. Lu, Computerized simulation of generation, meshing and contact of double circular-arc helical gears, Math. Comput. Model. 18, 31-47 (1993)

[7] Y. Ariga, S. Nagata, Load capacity of a new W-N gear with basic rack of combined circular and involute profile, J. Mech. Trans. Autom. 107, 565-572 (1985)

[8] C.B. Tsay, Z.H. Fong, Computer simulation and stress analysis of helical gears with pinion circular arc teeth and gear involute teeth, Mech. Mach. Theory 26, 145-154 (1991)

[9] Q. Luo, H. Li, J. Wang, Y. Zhang, H. Huang, Transmission of point-line meshing gear, The Int. J. Adv. Manufactur. Technol. 33, 845-855 (2007)

[10] Y.C. Wu, K.Y. Chen, C.B. Tsay, Y. Ariga, Contact characteristics of circular-arc curvilinear tooth gear drives, J. Mech. Des. 131, 181003 (2009)

[11] S.C. Yang, Mathematical model of a stepped triple circulararc gear, Mech. Mach. Theory 44, 1019-1031 (2009)

[12] H. Zhang, L. Hua, X. Han, Computerized design and simulation of meshing of modified double circular-arc helical gears by tooth end relief with helix, Mech. Mach. Theory 45, 46-64 (2010)

[13] X. Chen, Y. Liu, J. Xing, S. Lin, W. Xu, The parametric design of double-circular-arc tooth profile and its influence on the functional backlash of harmonic drive, Mech. Mach. Theory 73, 1-24 (2014)
[14] T. Komori, Y. Ariga, S. Nagata, A new gears profile having zero relative curvature at many contact points (logiX tooth profile), J. Mech. Des. 112, 430-436 (1990)

[15] C. Lee, H.H. Lin, F.B. Oswald, D.P. Townsend, Influence of linear profile modification and loading conditions on the dynamic tooth load and stress of high-contact-ratio spur gears, J. Mech. Des. 113, 473-480 (1991)

[16] M.H. Tsai, Y.C. Tsai, Design of high-contact-ratio spur gears using quadratic parametric tooth profiles, Mech. Mach. Theory 33, 551-564 (1998)

[17] N. Yildirim, R.G. Munro, A systematic approach to profile relief design of low and high contact ratio spur gears, Proc. Inst. Mech. Eng. C 213, 551-562 (1999)

[18] A. Kapelevich, Geometry and design of involute spur gears with asymmetric teeth, Mech. Mach. Theory 35, 117-130 (2000)

[19] T. Yeh, D.C.H. Yang, S.H. Tong, Design of new tooth profiles for high-load capacity gears, Mech. Mach. Theory 36, 1105-1120 (2001)

[20] S. Barone, Gear geometric design by B-spline curve fitting and sweep surface modelling, Eng. Comput. 17, 66-74 (2001)

[21] Z.H. Fong, T.W. Chiang, C.W. Tsay, Mathematical model for parametric tooth profile of spur gear using line of action, Math. Comput. Model. 36, 603-614 (2002)

[22] S. Luo, Y. Wu, J. Wang, The generation principle and mathematical models of a novel cosine gear drive, Mech. Mach. Theory 43, 1543-1556 (2008)

[23] G. Hlebanja, S-gears for wind power turbine operation conditions, Mach. Des. 4, 123-130 (2012)

[24] J. Wang, L. Hou, S. Luo, R.Y. Wu, Active design of tooth profiles using parabolic curve as the line of action, Mech. Mach. Theory 67, 47-63 (2013)

[25] L. Liu, F. Meng, J. Ni, A novel non-involute gear designed based on control of relative curvature, Mech. Mach. Theory 140, 144-158 (2019)

[26] Y. Wang, S. Ren, Y. Li, Design and manufacturing of a novel high contact ratio internal gear with a circular arc contact path, Int. J. Mech. Sci. 153-154, 143-153 (2019)

[27] I.R. Shabanov, On the gear transmission with a conchoidal path of contact, Nadyozhnost i Kachestvo Zubchatych Peredach 18-67-106, 1-8 (1967) (in Russian)

[28] V.P. Shishov, P.L. Nosko, O.A. Revyakina, Cylindrical transmissions with arch teeth, Publishing House of Volodymyr Dahl East Ukrainian National University, Lugansk, 2004 (in Russian)

[29] H.J. Watson, Modern Gear Production, Pergamon Press, Oxford (1970)

[30] V.P. Shishov, O.A. Revyakina, P.N. Tkach, On the character of teeth contact in cylindrical transmissions, Bull. Natl. Tech. Univ. 21, 110-119 (2007) (in Russian)

[31] H. Linke, J. Börner, R. Heß, Cylindrical Gears: Calculation, Materials, Manufacturing, Carl Hanser Verlag, Munich (2016)

[32] Y.N. Drozdov, V.I. Smirnov, Study of the coefficient of sliding friction for high contact parameters, Vestnik Mashinostroeniya 6, 19-23 (1977) (in Russian)

[33] V. Onishchenko, Tooth wear modeling and prognostication parameters of engagement of spur gear power transmissions, Mech. Mach. Theory 43, 1639-1664 (2008)

Cite this article as: P. Tkach, P. Nosko, O. Bashta, Y. Tsybrii, O. Nosko, High load capacity spur gears with conchoidal path of contact, Mechanics \& Industry 22, 47 (2021) 